\title{
High level of interleukin-32 gamma in the joint of ankylosing spondylitis is associated with osteoblast differentiation
}

\author{
Eun-Ju Lee ${ }^{1 \dagger}$, Eun-Jin Lee ${ }^{2 \dagger}$, Yeon-Ho Chung ${ }^{2}$, Da-Hyun Song ${ }^{2}$, Seokchan Hong ${ }^{1}$, Chang-Keun Lee ${ }^{1}$, Bin Yoo ${ }^{1}$, \\ Tae-Hwan Kim ${ }^{3}$, Ye-Soo Park ${ }^{4}$ Soo-Hyun Kim ${ }^{5}$ Eun-Ju Chang ${ }^{2^{*}}$ and Yong-Gil Kim ${ }^{\text {1* }}$
}

\begin{abstract}
Backgound: The formation of bony spurs and ankylosis is a key pathognomic feature in ankylosing spondylitis (AS) and results in functional impairment. The aim of this study was to investigate the role of IL-32y in osteoblast (OB) differentiation and its association with the pathogenesis of AS.

Methods: The concentration and expression of IL-32 $\gamma$ were evaluated in synovial fluid and tissue from patients with AS, rheumatoid arthritis (RA) and osteoarthritis (OA), using enzyme-linked immunosorbent assay and immunohistochemistry. To establish whether IL-32 $\gamma$ affects OB differentiation, we used calvarial cells of IL-32 $\gamma$ transgenic (TG) mice or wild-type (WT) mice. To elucidate the mechanism of osteoblastogenesis, levels of regulators were assayed in IL-32Y TG mice and in primary OBs after IL-32y stimulation.

Results: The IL-32y levels were higher in the synovial fluid of AS patients compared with RA or OA patients and the expression of IL-32 was higher in AS synovia than in RA or OA synovia. Additional IL-32y stimulation in precursor cells enhanced $O B$ differentiation potentially and IL-32y TG mice showed higher rates of OB differentiation than WT mice. IL-32y reduced the expression of DKK-1, a negative regulator, in both WT precursor cells and human OBs and the constitutive expression of DKK-1 was suppressed in calvarial cells from IL-32y TG mice.
\end{abstract}

Conclusions: The elevated level of IL-32 $\gamma$ in AS joint could enhance OB differentiation via DKK-1 suppression. Therefore, IL-32y might be a putative molecular target to prevent the abnormal bone formation in AS.

Keywords: Interleukin-32, Osteoblast differentiation, Ankylosing spondylitis

\section{Backgound}

Ankylosing spondylitis (AS) is a chronic inflammatory form of arthritis that primarily affects the spine. The formation of bony spurs and ankylosis, which cause functional impairment in AS patients, are the characteristic axial findings of AS. Besides the axial skeleton, peripheral joints are also involved in about $30-50 \%$ of primary AS during the disease course, which is usually follows an asymmetric and oligoarticular pattern $[1,2]$. Interestingly,

\footnotetext{
*Correspondence: ejchang@amc.seoul.kr; bestmd2000@amc.seoul.kr ${ }^{\dagger}$ Equal contributors

${ }^{2}$ Department of Biomedical Sciences, Cell Dysfunction Research Center and BMIT, University of Ulsan College of Medicine, Asan Medical Center, 88 Olympic-ro 43 gil, Songpa-gu, Seoul 05505, Korea

'Department of Rheumatology, University of Ulsan College of Medicine, Asan Medical Center, 88 Olympic-ro 43 gil, Songpa-gu, Seoul 05505, Korea
} Full list of author information is available at the end of the article new bone formation at entheseal sites of the peripheral joint was commonly seen in AS [3].

The new bone formation in AS might be related to active repair following the damage caused by inflammation $[4,5]$; that is, inflammation and bone formation appear to occur at different times, with the former preceding the latter. However, direct bone damage does not seem to be essential, given that inhibition of the activity of the osteoclasts did not prevent bone formation in animal experiments [6]. Therefore, the mechanism that underlies the proliferative bone formation in AS remain uncertain.

Bone formation requires the differentiation and activation of osteoblasts (OBs), which synthesize the bone matrix and originate from mesenchymal stem cells. The differentiation and activation of OBs are regulated by various molecules. Of these, parathyroid hormone, bone morphogenetic 
protein (BMP), and members of the Wnt protein family are the most prominent factors. Wnt proteins activate at least three distinct pathways: the canonical ( $\beta$-catenindependent), calcium-dependent, and planar polarity pathways [7]. Of these, the canonical pathway is best understood. Briefly, when Wnt molecules bind to Frizzled and Lrp5/6 on the surface of osteoprogenitors, stabilized $\beta$-catenin translocates into the nucleus and enhances the transcription of genes related to OB formation [8]. Dickkopf-1 (DKK-1) is a product of OBs that is a potent Wnt pathway inhibitor and inhibits proper differentiation of OBs. Mice that overexpress DKK-1 in OBs develop osteopenia because of reduced OB abundance and decreased bone formation [9]. Blocking DKK-1 transforms the bone-destruction pattern to a bone-creation pattern in a mouse model [10].

Interleukin (IL)-32, which exhibits the properties of a proinflammatory cytokine, is produced by $\mathrm{T}$ lymphocytes, natural killer cells, epithelial cells, blood monocytes and fibroblast-like synoviocytes in the joints and affects various inflammatory cascades [11-13]. Previously, we reported that IL-32 $\gamma$, the biologically active isoform of IL-32, is a potent mediator of osteoclast differentiation $[14,15]$. However, the biologic function of IL-32 $\gamma$ on OBs, the other side of bone balance, has never been investigated.

We report here that IL-32 $\gamma$ accumulates in the joint fluid and is expressed in the synovia of AS patients at much higher levels than in the synovia of rheumatoid arthritis (RA) patients. We first investigated the potentially pathogenic role of IL-32 $\gamma$ in AS, focusing on OB differentiation using $I L-32 \gamma$ transgenic (TG) mice.

\section{Methods}

\section{Sample collection and enzyme-linked immunosorbent assay}

All biologic samples from patients were obtained in accordance with the approval of the Asan Medical Center Institutional Review Board (S2013-0986-0003). Informed consent was obtained from all patients. Peripheral synovial tissues (from patients who underwent synovectomy), soft tissues from the axial skeleton (from patients who performed laminectomy) and knee joint fluids were collected at the Asan Medical Center and Hanyang University Hospital. Diagnoses either met the modified New York criteria for AS [16], the 1987 revised criteria for RA [17], or criteria for osteoarthritis (OA) [18]. Clinical information at the time of arthrocentesis was extracted from an electronic clinical database. The concentrations of IL-32 $\gamma$ and tumor necrosis factor (TNF)- $\alpha$ were measured using commercially available kits obtained from YbdY (Seoul, South Korea) and R\&D Systems (Minneapolis, MN, USA). A commercial enzyme-linked immunosorbent assay (ELISA) kit (R\&D Systems) was also used to determine the murine DKK-1 proteins secreted in culture media.

\section{Immunohistochemistry assay}

Sections of paraffin-embedded synovial tissue samples from OA, RA, and AS patients were stained with antiIL-32 antibody (Millipore, Billerica, MA, USA) or normal rabbit IgG (Santa Cruz Biotechnology, Dallas, TX, USA) according to manufacturer's instructions. Tissue sections ( $5 \mu \mathrm{m}$ thick) were baked at $65{ }^{\circ} \mathrm{C}$ for $30 \mathrm{~min}$, and the paraffin was removed by two washes ( 5 min each) with $x y-$ lene. The sections were rehydrated by passage through a graded series of ethanol solutions (100\% to $70 \%$ ethanol) and, for antigen retrieval, slides were dipped in citrate buffer (pH 6.0) and incubated at $95{ }^{\circ} \mathrm{C}$ for $5 \mathrm{~min}$. For permeabilization, the samples were incubated for $10 \mathrm{~min}$ in phosphate-buffered saline (PBS) that contained $0.25 \%$ Triton X-100 (PBST), and were washed twice with PBS, with each wash lasting 5 min. To block nonspecific binding of the antibodies, the samples were incubated with $1 \%$ bovine serum albumin (BSA) in PBST for $1 \mathrm{~h}$ and washed twice with PBST, with each wash lasting $5 \mathrm{~min}$. To eliminate endogenous peroxidase activity, the tissue sections were incubated with $3 \% \mathrm{H}_{2} \mathrm{O}_{2}$ in PBS for $30 \mathrm{~min}$ and washed twice with PBST, with each wash lasting $5 \mathrm{~min}$. The sections were incubated with antiIL-32 (1:100 in PBST) or normal rabbit IgG (1:100 in PBST) for $30 \mathrm{~min}$ at room temperature, and then washed twice with PBST (with each wash lasting $5 \mathrm{~min}$ ). Thereafter, the samples were incubated for $30 \mathrm{~min}$ at room temperature with anti-mouse or anti-rabbit secondary antibodies that were conjugated to polymeric horseradish peroxidase (Dako, Glostrup, Denmark). For colorimetric detection of the enzymatic reactions, the sections were incubated with Dako liquid DAB+ substrate chromogen solution (Dako) for $30 \mathrm{~min}$, before two washes $(5 \mathrm{~min}$ each) with PBS. The samples were counterstained with hematoxylin (Sigma, St Louis, MO, USA) for $1 \mathrm{~min}$, and then washed twice with distilled water (each wash for $5 \mathrm{~min}$ ). To stain the nuclei blue, the slides were dipped once in $0.3 \%$ ammonia in water.

\section{Animals}

IL-32 $\gamma$ TG and wild-type (WT) C57BL/6 mice were obtained from Dr. Kim's laboratory (Konkuk University, Korea) and SLC, Inc. (Japan), respectively. All experiments using mice were performed in accordance with the relevant guidelines and regulations on the use of animals at the Asan Biomedical Research Institute of the Asan Medical Center (Korea) and were approved by the Institutional Animal Care and Use Committee of the Asan Biomedical Research Institute of the Asan Medical Center (2013-02008). 


\section{Osteoblast differentiation}

$O B$ differentiation was performed by isolating primary mouse OB precursor cells from the calvariae of 1-day-old mice in accordance with a published protocol [19]. Osteoblastic precursor cells of WT and $I L-32 \gamma$ TG mice were isolated from calvaries by six routine sequential digestions with $0.1 \%$ collagenase (Gibco BRL, Gaithersburg, MD, USA) and $0.2 \%$ dispase (Roche, Penzberg, Germany). To induce $\mathrm{OB}$ differentiation, these cells were seeded onto 48-well culture plates at a density of $2 \times 10^{4}$ cells/well and cultured in osteogenic medium ( $\alpha$-MEM, $10 \%$ fetal bovine serum (FBS), $10 \mathrm{mM} \beta$-glycerophosphate, and $50 \mathrm{mg} / \mathrm{ml}$ ascorbic acid) for 1 to 4 weeks. The medium was changed every 3 days. $\mathrm{OB}$ differentiation and mineralization were assessed by detecting alkaline phosphatase (ALP) activity or by staining with Alizarin Red (AR) or Von Kossa (VK) stain.

Human OBs were purchased from Promo Cell (Heidelberg, Germany). Cells were cultured in OB growth medium (C-27001) containing fetal calf serum and $100 \mathrm{U} / \mathrm{ml}$ of the penicillin-streptomycin at $37{ }^{\circ} \mathrm{C}$ in a humidified atmosphere under $5 \%(\mathrm{v} / \mathrm{v}) \mathrm{CO}_{2}$. Human OBs were treated with IL-32 $(50$ or $100 \mathrm{ng} / \mathrm{mL}$ ) for $8 \mathrm{~h}$.

\section{Reverse transcription-polymerase chain reaction analysis}

Total RNA was isolated from the cells using QIAzol Lysis reagent (Qiagen, Valencia, CA, USA) and $2 \mu \mathrm{g}$ was reverse-transcribed using SuperScript II reverse transcriptase (Life Technologies, Carlsbad, CA, USA) according to manufacturer's instructions. The cDNA generated was amplified by polymerase chain reaction (PCR) using the primers shown in Table 1. The PCR conditions were as follows: denaturation at $94{ }^{\circ} \mathrm{C}$ for $30 \mathrm{~s}$, followed by annealing at $55-60{ }^{\circ} \mathrm{C}$ for $30 \mathrm{~s}$, and extension at $72{ }^{\circ} \mathrm{C}$ for $1 \mathrm{~min}$. The number of cycles fell within the range associated with linear amplification (28-34 cycles; GAPDH required 23 cycles).

\section{Western blotting analysis}

WT calvarial $\mathrm{OB}$ precursor cells were stimulated with IL-32 $(100 \mathrm{ng} / \mathrm{ml})$ and wnt3a $(20 \mathrm{ng} / \mathrm{ml})$ in osteogenic media. At the indicated times, the cells were washed with ice-cold PBS and lysed in modified RIPA buffer (50 mM Tris/HCl (pH 7.4), 1 \% Nonidet P40, $0.25 \%$ sodium deoxycholate, and $150 \mathrm{mM} \mathrm{NaCl}$ ) containing protease and phosphatase inhibitors. Cell lysates were centrifuged at $10,000 \mathrm{~g}$ for $15 \mathrm{~min}$, the supernatants were collected, and the proteins resolved in $10 \%$ SDSPAGE gels. Separated proteins were transferred to a polyvinylidene difluoride membrane (Bio-Rad, Hercules, CA USA), and then blocked for $1 \mathrm{~h}$ with $5 \%$ BAS (MP biomedicals, Auckland, New Zealand) solution in Trisbuffered saline solution containing $0.1 \%$ Tween 20 . The membrane was then incubated overnight at $4{ }^{\circ} \mathrm{C}$ with
Table 1 List of primers used for the detection of DKK-1, BMP-2, BMPRII and LRP-5

\begin{tabular}{ll}
\hline Target & Sequences \\
\hline Mouse DKK-1 & Forward 5'-GAG GGG AAA TTG AGG AAA GC-3' \\
& Reverse 5'-GCA GGT GTG GAG CCT AGA AG-3' \\
Mouse BMP-2, & Forward 5'-GGG ACC CGC TGT CTT CTA GT-3' \\
& Reverse 5'-TCA ACT CAA ATT CGC TGA GGA C-3' \\
Mouse BMPRII & Forward 5'-TTG GGA TAG GTG AGA GTC GAA T-3' \\
& Reverse 5'-TGT TTC ACA AGA TTG ATG TCC CC-3' \\
Mouse LRP-5 & Forward 5'-CAG GTG CTT GTG TGG AGA GA-3' \\
& Reverse 5'-GTC CAT GAC GAA GTC CAG GT-3' \\
Mouse GAPDH & Forward 5'-AGC CAC ATC GCTCAG ACA-3' \\
& Reverse 5'-GCC CAA TAC GAC CAAATC C-3' \\
Human DKK-1 & Forward 5'-CAT CAG ACT GTG CCT CAG GA-3' \\
& Reverse 5'-CCA CAG TAA CAA CGC TGG AA-3' \\
Human GAPDH & Forward 5'-CGT CTT CAC CAC CAT GGA GA-3' \\
& Reverse 5'-CGG CCA TCA CGC CAC AGT TT-3'
\end{tabular}

$B M P$ bone morphogenetic protein, BMPRII bone morphogenetic protein receptor II, DKK-1 Dickkopf-1, LRP-5 low-density lipoprotein receptor-related protein 5

antibodies specific for active $\beta$-catenin (Non-phospho, Ser33/37/Thr41, Cell Signaling), total $\beta$-catenin, and $\beta$ actin, washed, and incubated for $1 \mathrm{~h}$ at room temperature with the horseradish peroxidase-conjugated secondary antibody. Reactive proteins were visualized using a chemiluminescence system (Merck-Millipore, Darmatadt, Germany).

\section{Statistical analysis}

The differences between two groups were calculated using the Mann-Whitney $U$-test or an unpaired Student's $t$-test, and the differences among three groups were analyzed by one-way analysis of variance. The relationships among parameters were tested by using Spearman's rank correlation coefficient. Statistical analyses were considered significant for $p$ values $<0.05$.

\section{Results}

\section{IL-32 in the synovial fluids and tissues}

To evaluate the involvement of IL-32 in AS pathogenesis, we first determined the levels of IL-32 $\gamma$ and TNF- $\alpha$ in the joint fluids from patients with AS, RA, and OA. As shown in Fig. 1a, the levels of IL-32 $\gamma$ were significantly higher in AS patients than in either RA or OA patients $(p<0.01)$. The levels of TNF- $\alpha$ in the joint fluids from patients with AS or RA were higher than those from patients with OA. However, there was no difference in the TNF- $\alpha$ level between patients with AS and those with RA (Fig. 1b).

Table 2 summarizes the baseline characteristics of the AS patients $(n=15)$ and RA patients $(n=17)$ who underwent arthrocentesis. In the AS patients, none of the clinical parameters, including age, sex, levels of inflammatory 

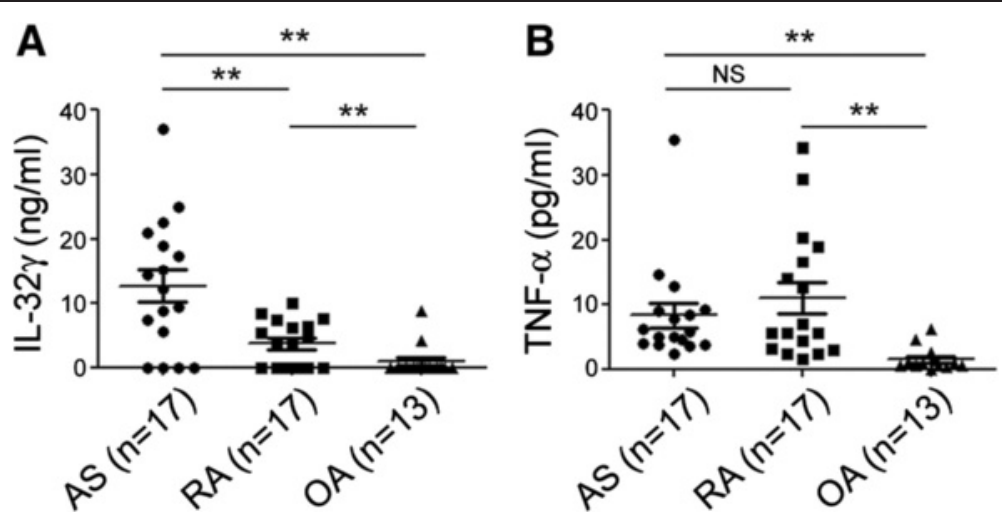

Fig. 1 IL-32 in the synovial fluids of ankylosing spondylitis patients. a IL-32 levels in joint fluid and $\mathbf{b}$ TNF-a levels in joint fluid. Levels of human IL-32 $\gamma$ and TNF-a in the joint fluid of patients with AS $(n=15), R A(n=17)$, and OA $(n=13)$ were measured using a commercially available ELISA kit. The bars show the means $\pm S D ;{ }^{* *} p<0.01$. AS ankylosing spondylitis, IL interleukin, NS not significant, OA osteoarthritis, RA rheumatoid arthritis, TNF tumor necrosis factor

markers, grade of sacroiliitis, eye involvement, HLA B27 allele, Bath Ankylosing Spondylitis Disease Activity Index score [20], and modified Stoke Ankylosing Spondylitis Spine Score (mSASSS) [21], was found to be associated with the IL-32 $\gamma$ levels in the peripheral joint fluids (Table 2). Considering mismatch between mSASSS and

Table 2 Baseline characteristics of patients with ankylosing spondylitis and rheumatoid arthritis

\begin{tabular}{llll}
\hline & AS $(\mathrm{n}=15)$ & $\mathrm{RA}(\mathrm{n}=17)$ & $p$-value \\
\hline Age (years, mean $\pm \mathrm{SD})$ & $32.9 \pm 9.6$ & $56.2 \pm 10.4$ & $<0.0001$ \\
Sex $($ male, $\mathrm{n}(\%))$ & $12(80.0 \%)$ & $2(11.8 \%)$ & $<0.0001$ \\
ESR $(\mathrm{mm} / \mathrm{h}$, mean $\pm \mathrm{SD})$ & $53.7 \pm 35.5$ & $56.5 \pm 31.3$ & $\mathrm{NS}$ \\
CRP $(\mathrm{mg} / \mathrm{dL}$, mean $\pm \mathrm{SD})$ & $3.5 \pm 3.5$ & $2.9 \pm 3.4$ & $\mathrm{NS}$ \\
Disease duration (years, mean $\pm \mathrm{SD})$ & $5.2 \pm 6.1$ & $6.1 \pm 6.3$ & $\mathrm{NS}$ \\
Eye involvement $(\mathrm{n}(\%))$ & $5(33.3 \%)$ & $\mathrm{N} / \mathrm{A}$ & \\
HLA-B27 positive $(\mathrm{n}(\%))$ & $13(86.7 \%)$ & $\mathrm{N} / \mathrm{A}$ & \\
BASDAl (mean $\pm \mathrm{SD})$ & $4.3 \pm 2.3$ & $\mathrm{~N} / \mathrm{A}$ & \\
mSASSS (mean $\pm \mathrm{SD})$ & $15.8 \pm 16.7$ & $\mathrm{~N} / \mathrm{A}$ & \\
Sacroiliitis grading (n (\%)) & & & \\
Grade 2 & $3(20.0 \%)$ & $\mathrm{N} / \mathrm{A}$ & \\
Grade 3 & $9(60.0 \%)$ & $\mathrm{N} / \mathrm{A}$ & \\
Grade 4 & $3(20.0 \%)$ & $\mathrm{N} / \mathrm{A}$ & \\
Current medications (n (\%)) & & & \\
MTX & $7(46.7 \%)$ & $14(82.4 \%)$ & 0.062 \\
SSZ & $8(53.3 \%)$ & 1 (5.9\%) & 0.005 \\
TNFi & $3(20 \%)$ & 1 (5.9\%) & 0.319 \\
NSAID & $13(86.7 \%)$ & $16(94.1 \%)$ & 0.589 \\
\hline AS & & & \\
\hline
\end{tabular}

AS ankylosing spondylitis, BASDAl bath ankylosing spondylitis disease activity index, CRP C-reactive protein, ESR erythrocyte sedimentation rate, $m S A S S S$ modified Stoke Ankylosing Spondylitis Spine Score, MTX methotrexate, N/A not available, NS not significant, NSAID nonsteroidal anti-inflammatory drug, RA rheumatoid arthritis, SSZ sulfasalazine, TNFi tumor necrosis factor inhibitor
IL-32 levels of peripheral joint fluid, peripheral arthritis could not reflect the severity of the axial joint directly.

We next performed immunohistochemical (IHC) staining to investigate the levels of IL-32 protein in the joint tissues from patients with AS, RA, and OA. The IHC analysis revealed that the IL-32 level was higher in AS synovial tissues than in RA or OA synovial tissues (Fig. 2a). The stained cells in the synovial tissue possess spindleshaped morphology and these are mostly consistent with synovial fibroblasts. Further, as shown in Fig. 2b, high IL-32 level was also detected in axial skeletons around the facet joint of AS patients compared to those of OA patients.

\section{Osteoblast differentiation by IL-32 $\gamma$ is accompanied by the suppression of $D K K-1$ expression}

To understand the direct role of IL-32 $\gamma$ during OB differentiation, calvarial cells of WT mice were treated with IL-32 $\gamma(100 \mathrm{ng} / \mathrm{ml})$ in osteogenic media, and changes in ALP activity, calcium deposition (determined by AR staining), and mineral deposition (determined by VK staining) were monitored for 4 weeks. As shown in Fig. 3a, exposure to exogenous IL-32 $\gamma$ promoted rapid and marked $\mathrm{OB}$ differentiation and matrix maturation, as indicated by increased ALP activity and increased numbers of AR- and VK-positive cells. Moreover, regions positive for AR staining were observed only after 2 weeks of IL-32 $\gamma$ treatment. These results clearly support a role for IL-32 $\gamma$ in promoting OB differentiation. We next investigated possible regulators that are related to the IL-32 $\gamma$ pathway at the mRNA level. The results revealed the IL-32 $\gamma$ induced suppression of $D K K-1$, a specific inhibitor of Wnt/ $\beta$-catenin signaling that is secreted by OBs. Specifically, the mRNA levels of this protein were dramatically lower in the calvarial cells (Fig. 3b), and there was a decrease in the DKK-1 


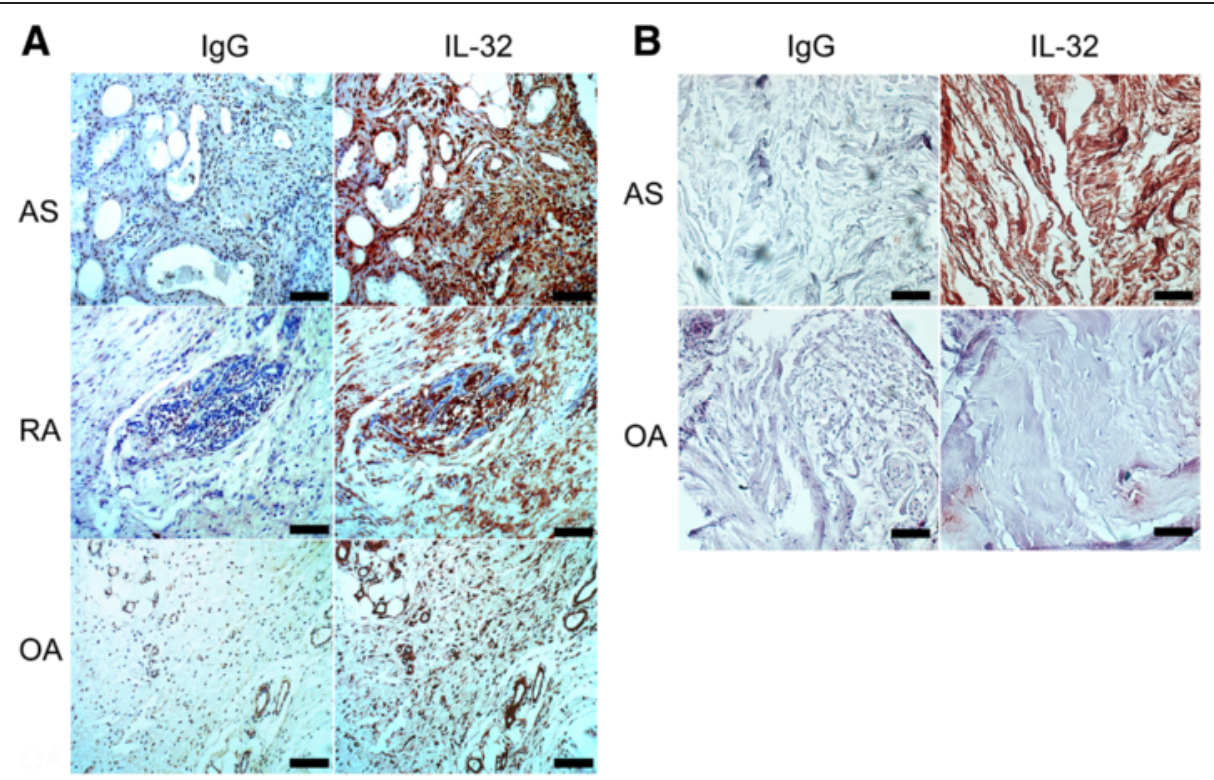

Fig. 2 High IL-32 in the peripheral synovia and the axial skeletons of ankylosing spondylitis. a Representative immunohistochemical (IHC) images of peripheral synovia of AS, RA, or OA stained with antibodies against IL-32 or isotype controls. Synovitis was found in the tissues acquired from the patients with clinically active AS (36-year-old female, ankle) and RA (52-year-old female, ankle). b Representative IHC images of axial skeletons of advanced AS (57-year-old female) and OA (79-year-old female) patients who underwent laminectomy. All IHC images are shown at 200x magnification (scale bars, $100 \mu \mathrm{m}$ ), and are representative of images from three independent experiments. AS ankylosing spondylitis, IL interleukin, $O A$ osteoarthritis $R A$, rheumatoid arthritis

protein level in culture media after IL-32 $\gamma$ treatment (Fig. 3c). These results suggested that IL-32 $\gamma$ might regulate mouse $D K K-1$ expression. To further validate the mechanism by which IL-32 $\gamma$ enhances OB differentiation in humans, we also determined the abundances of $D K K-1$ mRNAs in human OBs and found the stimulation with IL-32 $\gamma$ reduced the abundance of DKK-1 mRNAs (Fig. 3d). To confirm the downstream effects of DKK-1 suppression, the level of active $\beta$-catenin was evaluated after the treatment with IL-32 $\gamma$ or Wnt3a (positive control). As shown in Fig. 3e, IL-32 $\gamma$ enhanced $\beta$-catenin activation significantly at $48 \mathrm{~h}$, which could be related to suppression of $D K K-1$.

\section{Enhanced osteogenic differentiation in $I L-32 \gamma$ transgenic mice}

Given the increased bone volume observed in $I L-32 \gamma$ TG mice, we next determined the role of $\mathrm{OB}$ differentiation in this phenomenon. The levels of ALP specific activity, calcium deposition, and mineral deposition indicated higher rates of osteogenic differentiation in $I L-32 \gamma$ TG mice than in WT mice (Fig. 4a). Reverse transcription PCR analysis revealed similar levels of the transcripts of genes that regulate $\mathrm{OB}$ differentiation-including $B M P-2, B M P R I I$, and $L R P-5$ - in the calvarial cells of the TG mice and WT mice after $24 \mathrm{~h}$ culture in osteogenic media. Interestingly, similarly to the endogenous reduction in $D K K-1$ expression in the OB precursor cells induced by IL-32 $\gamma$ stimulation, the induction of $D K K-1$ was dramatically lower in the calvarial cells from $I L-32 \gamma$ TG mice than those from WT mice (Fig. 4b). Furthermore, the DKK-1 protein level in the culture media from $I L-32 \gamma$ TG mice after 1 week of OB differentiation was also decreased (Fig. 4c). This finding suggests that the stimulation of osteogenic differentiation in $I L-32 \gamma$ TG mice might be linked to the reduction in the level of DKK-1 in the OB precursor cells.

\section{Discussion}

The current study showed that the proinflammatory cytokine IL-32 is accumulated in inflamed joints in patients with AS more than in those with RA or OA that were selected as the comparison groups; RA is not a bone-forming disease but an inflammatory disease, whereas $\mathrm{OA}$ is less inflammatory but is a bone-forming disease. The IL-32 level in RA joints could be expected to be lower than that in $\mathrm{OA}$ when considering the aspect of bone formation. However, our findings revealing higher levels of IL-32 in RA joints than in OA joints are consistent with previous reports $[12,14]$. We believe that the inflammatory cytokine IL-32 in RA joints could be accumulated by persistent inflammatory stimuli, although it was not enough to overcome bone loss and erosion. OA is characterized by osteophyte formation reflecting new bone formation, which is associated mainly with subchondral bone sclerosis, together with progressive cartilage damage [22], whereas new bone formation in AS involves a complicated and 


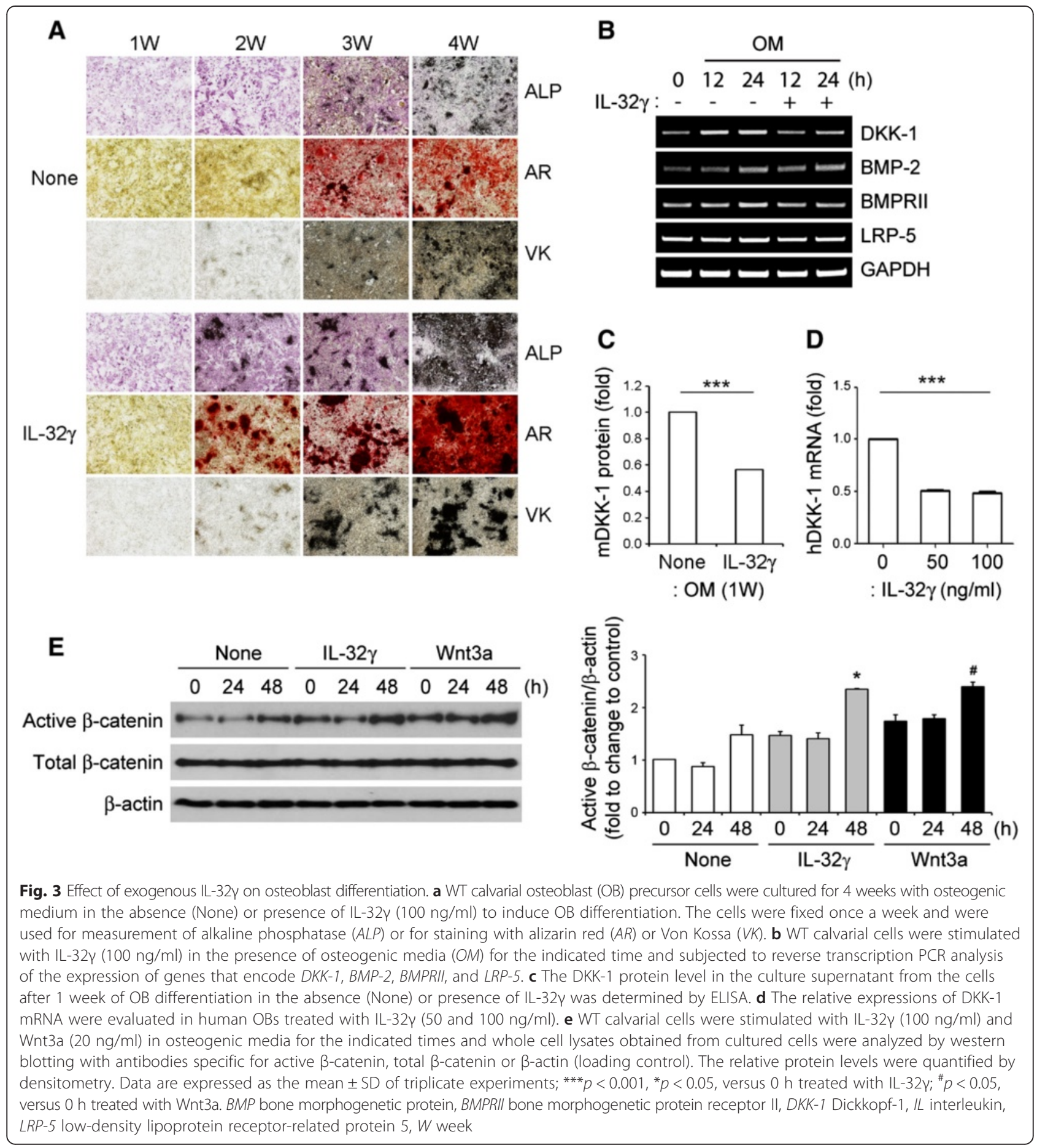

multifactorial sequence generated from the initiating entheseal inflammation.

Here, we verified the ability of IL-32 $\gamma$ to enhance OB differentiation and characterized how bone formation in AS differs from that in RA or OA. Our findings provide the first evidence, to our knowledge, of the high level of IL-32 $\gamma$ in AS peripheral and axial tissues and its association with abnormal bone formation. However, synovitis of peripheral joints could be a peripheral manifestation of disease, and does not correlate with axial joint severity and radiographic progression per se.

We demonstrated that $I L-32 \gamma$ TG mice had higher potency of osteogenic differentiation than WT mice and confirmed the enhanced $\mathrm{OB}$ differentiation triggered by the presence of the IL-32 $\gamma$ protein. An important aspect of IL-32 biology is that the induction of other 


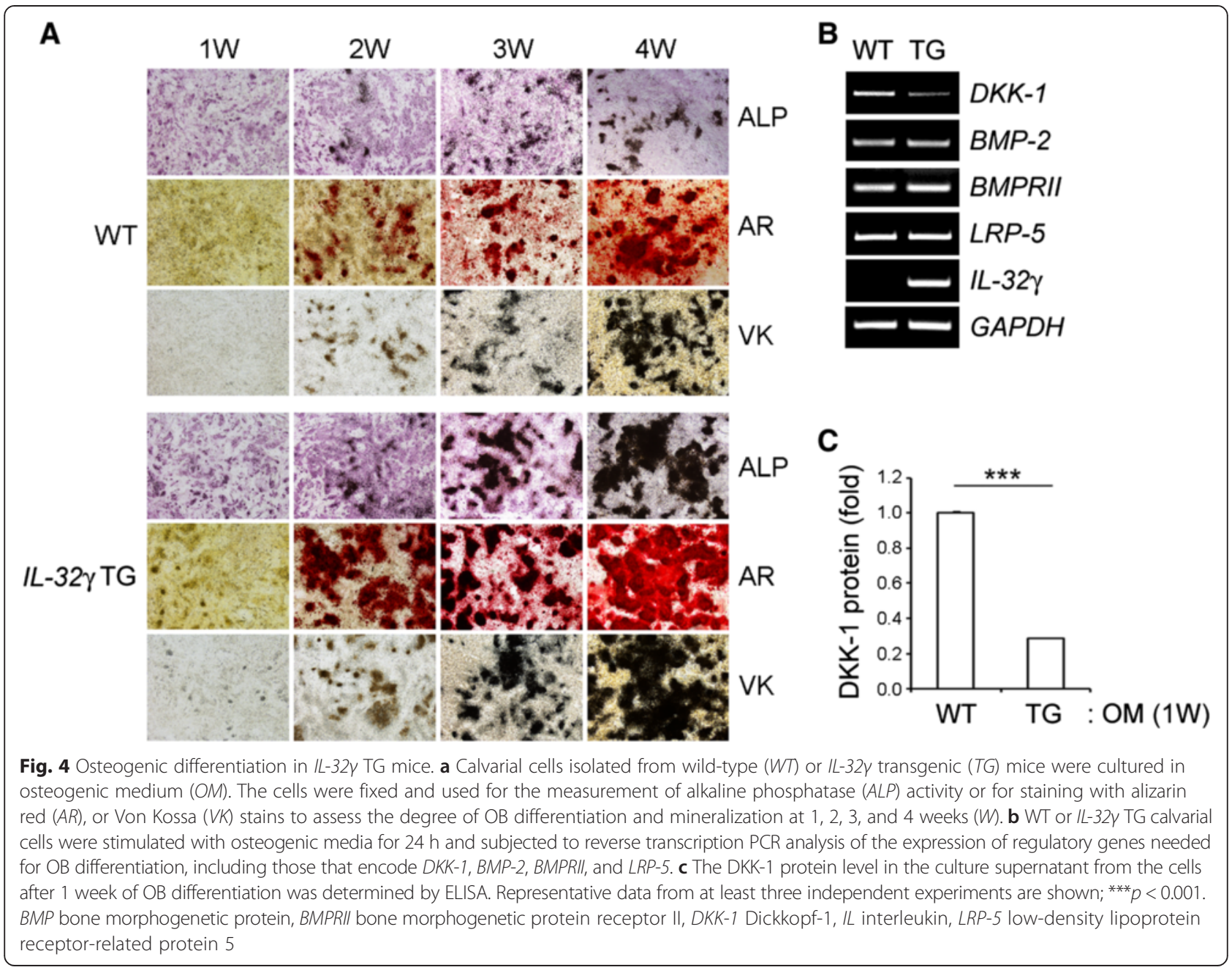

pro-inflammatory cytokines, including TNF, IL-1, IL-18, and IL-22, has been suggested in human RA [23], indicating the possible involvement of pro-inflammatory cytokines in IL-32 function. However, it is intriguing that the IL-32 TG mice, as well as IL-32 treatment, did not show any significant increases in the production of those cytokines under osteogenic stimulation conditions (Additional file 1). Interestingly, we found the reduction of IL-18 in IL-32 $\gamma$ TG mice and in cultures stimulated with IL-32, although this may not be significant. Unlike other inflammatory cytokines, IL-18 demonstrates positive effects on $\mathrm{OB}$ differentiation by mediating anabolic actions of parathyroid hormone [24]. In addition, IL-32 expression was correlated with IL-18 expression in the synovia of experimental arthritis animals and mucosa of patients with allergic rhinitis [25, 26]. However, we could not exclude the possibility that IL-32 and IL-18 regulate each other in a negative manner in OB differentiation. This assumption requires further investigation. Nevertheless, based on the knowledge of the inhibitory effects of pro-inflammatory cytokines (e.g., TNF, IL-1) on OB differentiation [27, 28], we can conclude that the osteogenic potential of IL-32 is unlike the activity of other pro-inflammatory cytokines.

A variety of chronic inflammatory diseases, including AS and RA, are currently treated by TNF inhibitors, especially in patients refractory to conventional treatments. Although TNF inhibitors are effective in controlling disease activity in AS, 2-year follow-up studies demonstrated no clear effect of this intervention on the development of bony ankylosis [29-31]. It was proposed that TNF suppresses OB differentiation by promoting DKK- 1 , which is a master negative regulator of the $\mathrm{Wnt} / \beta$-catenin pathway [10]. Furthermore, a recent study revealed that a TNF inhibitor significantly decreased the level of serum DKK-1 in AS patients [32]. The emerging view is that TNF inhibits new bone formation during the inflammatory process, but that TNF inhibitors can restore OB function despite their anti-inflammatory effects.

However, a long-term observational study by Haroon et al., in which large numbers of patients were analyzed over a 5-year follow-up period, reported that after adjusting for the baseline mSASSS the AS patients who were 
administered TNF inhibitors showed a $50 \%$ reduction in radiographic progression compared to those who had not received these agents [33]. To date, whether inflammation and new bone formation are uncoupled or occur simultaneously remains controversial. Therefore, considering the identified effects of IL-32 $\gamma$ on OBs and inflammation, treatments that target IL-32 $\gamma$ might prevent the uncoupling of inflammation from bony proliferation.

Although little is known about the mechanisms of syndesmophyte formation in the joints in AS, this likely involves regulatory molecules, such as Wnt proteins. Activation of Wnt signaling by blocking its natural inhibitor DKK-1 leads to the new bone formation in peripheral joints [10]. Interestingly, DKK-1 inhibition also leads to a bilateral erosive change and ankylosis of the sacroiliac joints in TNF TG mice, which have symptoms that mimic those of sacroiliitis in humans [34]. Given that DKK-1 is a key factor for joint remodeling during the inflammatory process, the AS phenotype might be related to certain conditions when DKK-1 has been suppressed or distorted functionally [35]. In this context, IL-32 $\gamma$ could be one of the important regulators that controls DKK-1 leading to modulation of the $\mathrm{Wnt} / \beta$-catenin signal during the pathogenesis of AS.

Despite our interesting results, the limitations of this study include that ectopic bone formation in the joints, which can be affected by $\mathrm{OB}$ activation, did not develop in our TG model spontaneously. Moreover, because of small sample size the levels of IL-32 in the peripheral joints were not correlated significantly with several clinical parameters including mSASSS, which might be obstacles to link our findings to clinical research. Finally, we could not exclude the effect of age and gender on the IL-32 production clearly, although there was no association in our samples.

\section{Conclusions}

Effective control of soluble factors that are related to bone proliferation might minimize disease progression in AS. Here, we show that AS joints have a higher level of IL-32 $\gamma$, and the differentiation of OB precursors from $I L-32 \gamma$ TG mice into mature OBs might be related to the suppression of $D K K-1$ expression. The higher levels of IL-32 $\gamma$ in the joints and tissues of the AS patients might induce $\mathrm{OB}$ differentiation and then trigger atypical new bone formation. These data suggest that IL-32 $\gamma$ might be a molecular target with the potential to prevent radiographic progression in AS.

\section{Additional file}

Additional file 1: The protein levels of inflammatory cytokines including TNF- $\alpha$, IL-1 $\beta$, IL-18 and IL-22 were determined in the culture supernatant from the cells of WT or IL-32 $\gamma$ TG mice (A) and the cells in the absence (None) or presence of IL-32Y (B) after 1 week of OB differentiation using commercial available ELISA kits. The bars show the means \pm SD of triplicate experiments. (TIFF $443 \mathrm{~kb}$ )

\section{Abbreviations}

ALP: Alkaline phosphatase; AR: Alizarin Red; AS: Ankylosing spondylitis; BMP: Bone morphogenetic protein; BMPRII: bone morphogenetic protein receptor II; DKK-1: Dickkopf-1; ELISA: Enzyme-linked immunosorbent assay; IHC: Immunohistochemical; IL: Interleukin; LRP-5: low density lipoprotein receptor-related protein 5; mSASSS: Modified Stoke Ankylosing Spondylitis Spine Score; OA: Osteoarthritis; OB: Osteoblast; PBS: Phosphate-buffered saline; PCR: Polymerase chain reaction; RA: Rheumatoid arthritis;

TG: Transgenic; TNF: Tumor necrosis factor; VK: Von Kossa; WT: Wild-type.

\section{Competing interests}

The authors declare that they have no competing interests.

\section{Authors' contributions}

EJiL and EJuL performed experiments, analyzed data, and wrote the manuscript. YHC and DHS contributed to performing the experiments in Figs. 3 and 4 and SH prepared Table 2. SHK provided the transgenic mice and interpreted the mouse data. CKL, BY, YSP and THK, as clinical supervisors, provided the human samples and integrated the data. YGK and EJC designed the study, contributed to data analysis, and wrote the manuscript. All authors were involved in drafting the article or critically revising it for important intellectual content, and all authors read and approved the final version to be published.

\section{Acknowledgements}

This research was supported by the National Research Foundation of Korea (NRF-2013R1A1A1009271) and the Asan Institute for Life Science (2014-463), with funding from both sources awarded to YGK. EJC received a grant from the Korean Health Technology R\&D Project, Ministry of Health \& Welfare of Korea (HI1 1C05070200). EJuL was supported by the National Research Foundation of Korea (NRF-2013R1A1A2059597).

\section{Author details}

'Department of Rheumatology, University of Ulsan College of Medicine, Asan Medical Center, 88 Olympic-ro 43 gil, Songpa-gu, Seoul 05505, Korea. ${ }^{2}$ Department of Biomedical Sciences, Cell Dysfunction Research Center and BMIT, University of Ulsan College of Medicine, Asan Medical Center, 88 Olympic-ro 43 gil, Songpa-gu, Seoul 05505, Korea. ${ }^{3}$ Department of Rheumatology, Hanyang University Hospital for Rheumatic Diseases, Seoul 133-791, Korea. ${ }^{4}$ Department of Orthopaedic Surgery, Guri Hospital, Hanyang University College of Medicine, Kyunggi-do 471-701, Korea. ${ }^{5}$ Department of Biomedical Science and Technology, Konkuk University, Seoul 143-701, Korea.

Received: 18 June 2015 Accepted: 20 November 2015

Published online: 04 December 2015

\section{References}

1. Ginsburg WW, Cohen MD. Peripheral arthritis in ankylosing spondylitis. A review of 209 patients followed up for more than 20 years. Mayo Clin Proc. 1983;58:593-6.

2. Mun SH, Ko NY, Kim HS, Kim JW, Kim do K, Kim AR, et al. Interleukin-33 stimulates formation of functional osteoclasts from human CD14(+) monocytes. Cell Mol Life Sci. 2010;67:3883-92. doi:10.1007/s00018-010-0410-y.

3. Helliwell PS, Porter G, group Cs. Sensitivity and specificity of plain radiographic features of peripheral enthesopathy at major sites in psoriatic arthritis. Skeletal Radiol. 2007;36:1061-6. doi:10.1007/s00256-007-0376-5.

4. Sieper J, Appel H, Braun J, Rudwaleit M. Critical appraisal of assessment of structural damage in ankylosing spondylitis: implications for treatment outcomes. Arthritis Rheum. 2008:58:649-56. doi:10.1002/art.23260.

5. Schett G, Rudwaleit M. Can we stop progression of ankylosing spondylitis? Best Pract Res Clin Rheumatol. 2010;24:363-71. doi:10.1016/j.berh.2010.01.005.

6. Schett G, Stolina M, Dwyer D, Zack D, Uderhardt S, Kronke G, et al. Tumor necrosis factor alpha and RANKL blockade cannot halt bony spur formation in experimental inflammatory arthritis. Arthritis Rheum. 2009;60:2644-54. doi:10.1002/art.24767.

7. Huang H, He X. Wnt/beta-catenin signaling: new (and old) players and new insights. Curr Opin Cell Biol. 2008;20:119-25. doi:10.1016/j.ceb.2008.01.009. 
8. Kubota T, Michigami T, Ozono K. Wnt signaling in bone metabolism. J Bone Miner Metab. 2009;27:265-71. doi:10.1007/s00774-009-0064-8.

9. Li J, Sarosi I, Cattley RC, Pretorius J, Asuncion F, Grisanti M, et al. Dkk1-mediated inhibition of Wnt signaling in bone results in osteopenia. Bone. 2006;39:754-66. doi:10.1016/j.bone.2006.03.017.

10. Diarra D, Stolina M, Polzer K, Zwerina J, Ominsky MS, Dwyer D, et al. Dickkopf-1 is a master regulator of joint remodeling. Nat Med. 2007;13:156-63. doi:10.1038/nm1538.

11. Kim SH, Han SY, Azam T, Yoon DY, Dinarello CA. Interleukin-32: a cytokine and inducer of TNFalpha. Immunity. 2005;22:131-42. doi:10.1016/j.immuni. 2004.12.003.

12. Mun SH, Kim JW, Nah SS, Ko NY, Lee JH, Kim JD, et al. Tumor necrosis factor alpha-induced interleukin-32 is positively regulated via the Syk/protein kinase Cdelta/JNK pathway in rheumatoid synovial fibroblasts. Arthritis Rheum. 2009:60:678-85. doi:10.1002/art.24299.

13. Kim YG, Lee CK, Kim SH, Cho WS, Mun SH, Yoo B. Interleukin-32gamma enhances the production of IL- 6 and IL-8 in fibroblast-like synoviocytes via Erk1/2 activation. J Clin Immunol. 2010;30:260-7. doi:10.1007/s10875-009-9360-2.

14. Kim YG, Lee CK, Oh JS, Kim SH, Kim KA, Yoo B. Effect of interleukin-32gamma on differentiation of osteoclasts from CD14+ monocytes. Arthritis Rheum. 2010;62:515-23. doi:10.1002/art.27197.

15. Kim YG, So MW, Koo BS, Chang EJ, Song SJ, Lee CK, et al. The influence of interleukin-32gamma on osteoclastogenesis with a focus on fusion-related genes. J Clin Immunol. 2012;32:201-6. doi:10.1007/s10875-011-9611-x.

16. van der Linden $S$, Valkenburg HA, Cats $A$. Evaluation of diagnostic criteria for ankylosing spondylitis. A proposal for modification of the New York criteria. Arthritis Rheum. 1984;27:361-8.

17. Arnett FC, Edworthy SM, Bloch DA, McShane DJ, Fries JF, Cooper NS, et al. The American Rheumatism Association 1987 revised criteria for the classification of rheumatoid arthritis. Arthritis Rheum. 1988;31:315-24.

18. Altman R, Asch E, Bloch D, Bole G, Borenstein D, Brandt K, et al. Development of criteria for the classification and reporting of osteoarthritis. Classification of osteoarthritis of the knee. Diagnostic and Therapeutic Criteria Committee of the American Rheumatism Association. Arthritis Rheum. 1986;29:1039-49.

19. Chang EJ, Ha J, Oerlemans F, Lee YJ, Lee SW, Ryu J, et al. Brain-type creatine kinase has a crucial role in osteoclast-mediated bone resorption. Nat Med. 2008;14:966-72. doi:10.1038/nm.1860.

20. Garrett S, Jenkinson T, Kennedy LG, Whitelock H, Gaisford P, Calin A. A new approach to defining disease status in ankylosing spondylitis: the Bath Ankylosing Spondylitis Disease Activity Index. J Rheumatol. 1994;21:2286-91.

21. Creemers MC, Franssen MJ, van't Hof MA, Gribnau FW, van de Putte LB, van Riel PL. Assessment of outcome in ankylosing spondylitis: an extended radiographic scoring system. Ann Rheum Dis. 2005;64:127-9. doi:10.1136/ ard.2004.020503.

22. Madry $\mathrm{H}$. The subchondral bone: a new frontier in articular cartilage repair Knee Surg Sports Traumatol Arthrosc. 2010;18:417-8. doi:10.1007/s00167010-1071-y.

23. Joosten LA, Netea MG, Kim SH, Yoon DY, Oppers-Walgreen B, Radstake TR, et al. IL-32, a proinflammatory cytokine in rheumatoid arthritis. Proc Natl Acad Sci U S A. 2006;103:3298-303. doi:10.1073/pnas.0511233103.

24. Raggatt LJ, Qin L, Tamasi J, Jefcoat Jr SC, Shimizu E, Selvamurugan N, et al. Interleukin-18 is regulated by parathyroid hormone and is required for its bone anabolic actions. J Biol Chem. 2008;283:6790-8. doi:10.1074/jbc. M709909200.

25. Park YE, Kim GT, Lee SG, Park SH, Baek SH, Kim SI, et al. IL-32 aggravates synovial inflammation and bone destruction and increases synovial natural killer cells in experimental arthritis models. Rheumatol Int. 2013;33:671-9. doi:10.1007/s00296-012-2385-5.

26. Jeong HJ, Shin SY, Oh HA, Kim MH, Cho JS, Kim HM. IL-32 up-regulation is associated with inflammatory cytokine production in allergic rhinitis. J Pathol. 2011;224:553-63. doi:10.1002/path.2899.

27. Gilbert L, He X, Farmer P, Boden S, Kozlowski M, Rubin J, et al. Inhibition of osteoblast differentiation by tumor necrosis factor-alpha. Endocrinology. 2000;141:3956-64. doi:10.1210/endo.141.11.7739.

28. Nakase T, Takaoka K, Masuhara K, Shimizu K, Yoshikawa H, Ochi T. Interleukin-1 beta enhances and tumor necrosis factor-alpha inhibits bone morphogenetic protein-2-induced alkaline phosphatase activity in MC3T3-E1 osteoblastic cells. Bone. 1997;21:17-21.
29. van der Heijde D, Landewe R, Einstein S, Ory P, Vosse D, Ni L, et al. Radiographic progression of ankylosing spondylitis after up to two years of treatment with etanercept. Arthritis Rheum. 2008;58:1324-31. doi:10.1002/art.23471.

30. van der Heijde D, Kivitz A, Schiff MH, Sieper J, Dijkmans BA, Braun J, et al. Efficacy and safety of adalimumab in patients with ankylosing spondylitis: results of a multicenter, randomized, double-blind, placebo-controlled trial. Arthritis Rheum. 2006;54:2136-46. doi:10.1002/art.21913.

31. Halvorsen EH, Haavardsholm EA, Pollmann S, Boonen A, van der Heijde $D$, Kvien TK, et al. Serum IgG antibodies to peptidylarginine deiminase 4 predict radiographic progression in patients with rheumatoid arthritis treated with tumour necrosis factor-alpha blocking agents. Ann Rheum Dis. 2009;68:249-52. doi:10.1136/ard.2008.094490.

32. Korkosz M, Gasowski J, Leszczynski P, Pawlak-Bus K, Jeka S, Siedlar M, et al. Effect of tumour necrosis factor-alpha inhibitor on serum level of dickkopf-1 protein and bone morphogenetic protein-7 in ankylosing spondylitis patients with high disease activity. Scand J Rheumatol. 2014;43:43-8. doi:10.3109/ 03009742.2013.805241.

33. Haroon N, Inman RD, Learch TJ, Weisman MH, Lee M, Rahbar MH, et al. The impact of tumor necrosis factor alpha inhibitors on radiographic progression in ankylosing spondylitis. Arthritis Rheum. 2013;65:2645-54. doi:10.1002/art.38070.

34. Uderhardt S, Diarra D, Katzenbeisser J, David JP, Zwerina J, Richards W, et al. Blockade of Dickkopf (DKK)-1 induces fusion of sacroiliac joints. Ann Rheum Dis. 2010;69:592-7. doi:10.1136/ard.2008.102046.

35. Daoussis D, Liossis SN, Solomou EE, Tsanaktsi A, Bounia K, Karampetsou M, et al. Evidence that Dkk-1 is dysfunctional in ankylosing spondylitis. Arthritis Rheum. 2010;62:150-8. doi:10.1002/art.27231.

\section{Submit your next manuscript to BioMed Central and we will help you at every step:}

- We accept pre-submission inquiries

- Our selector tool helps you to find the most relevant journal

- We provide round the clock customer support

- Convenient online submission

- Thorough peer review

- Inclusion in PubMed and all major indexing services

- Maximum visibility for your research

Submit your manuscript at www.biomedcentral.com/submit
C BioMed Central 